\title{
(Cognitive) mobilization and political blogs
}

\author{
Ramón Rufín Moreno • Cayetano Medina Molina • \\ Manuel Rey Moreno
}

\begin{abstract}
The literature has suggested many ways in which developing user commitment can benefit political bloggers. Existing models are based on generating attachment, satisfaction, and trust, but it is worth considering whether the relationships between these factors remain unchanged regardless of the other media used by blog visitors. In other words, our aim is to determine whether the fact that a blog visitor who reads print media and watches TV has a strong impact on developing commitment as it does on voting intention, both for the blogger and for the party he/she belongs to. The results we have obtained, in keeping with mobilization theory, suggest that access to the media leads to political mobilization rather than to the negative effects suggested by cognitive mobilization theory, or what is referred to as "video malaise". To be more specific, access to TV enhances the development of commitment, whereas reading print media leads to that commitment having a greater impact on attitudinal and behavioral variables.
\end{abstract}

Keywords Cognitive mobilization - Video malaise - Mobilization theory · Public marketing

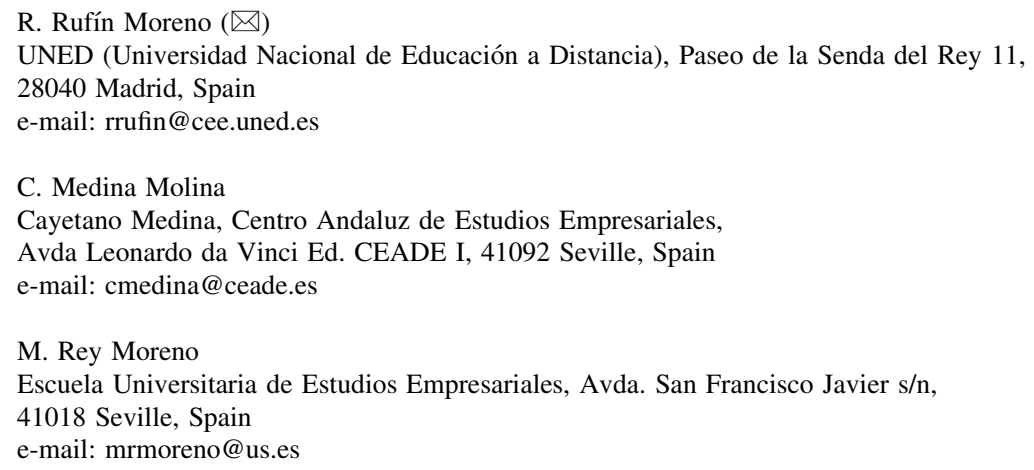




\section{Introduction}

Citizens of most modern democracies are experiencing an increasing sense of disaffection from their political processes and institutions. As a consequence, research has focused primarily on identifying both the underlying causes of this process and the factors that may help bringing politicians back in touch with their citizens. In this respect, Spanish citizens consider "politicians, political parties, and politics" as the third major concern among social affairs. In fact, on May, 1985 only $4.7 \%$ of Spanish citizens perceived the mentioned concern as one of the main problems to be worried about, a figure which is to be contrasted to that on November, 2012, 30.2\%. Many factors contribute to this trend, including changes in the media context, social mobility that erodes group identities, and the increasing complexity of social and political life (Dalton 2012).

One of the possible solutions that has been suggested involves the use of technology. By facilitating exposure and access to information, technology may generate an increase in knowledge of and interest in politics among citizens, leading to greater citizen and political participation, in other words, offering an additional vehicle for political involvement (Eveland and Thomson 2006; Kim and BallRokeach 2006; Rojas and Puig-i-Abril 2009; Sha et al. 2007).

With the Internet, the number of possible sources of information increases and, therefore, the number of consumers is distributed across a larger number of media outlets. This shapes new patterns of consumption that either give life to new consumers or move traditional consumers from old to new media. This change implies that traditional political organizations are less capable of managing and affecting the political arena, leaving space for new forms of social aggregations strictly depending on the new structure of the communication system (Mancini 2013). In a fragmented media market, each new (and old) media outlet is forced to find its own target/audience to distinguish its own product from the others (Mancini 2013).

If, as we just stated, blog visits offer multiple benefits for their authors, it is crucial to develop loyalty among those visitors. One of the variables that could generate greatest benefits in this respect is commitment; it could lead Internet users to refer exclusively to that blog (Aurier and N'Goala 2010). When this variable is dealt with in a political context, we must bear in mind the additional benefits related to its development in this field. Therefore, commitment is powerfully linked to votes, as well as to a broad range of behaviors that are highly relevant in a political context (Britt 2003).

However, further exploring the nature of Internet users-namely the impact that political blogs may have on visitors - calls for analyzing the potential moderating role of several different variables. Once again, we are faced with the controversy about the way in which access to information in different media may affect citizens' relationships with political parties and their representatives. Potential moderating effects, such as consumers' psychological, situational, and demographic characteristics, remain relatively unstudied. Researchers, therefore, call for further investigation of moderating effects, specifically highlight personal and situational characteristics as potential moderators (Zhang and Bloemer 2011). 
The decrease in the circulation of traditional paid newspapers has been largely compensated in many Western democracies by the birth and development of free newspapers; traditional analogical television has undergone similar transformations, with the development of new media, and Internet in particular, citizens have more choices in terms of cultural consumption (Mancini 2013).

The political role of the modern media and the impact on public opinion has come under intense scrutiny. The arguments in the scientific dispute have been structured under the optimistic "cognitive mobilization" and pessimistic "media malaise" banners (Jenssen 2009). These two approaches could hardly be more different. While the cognitive mobilization theory argues that access to a greater number of sources of information leads to dealignment from parties and their representatives, the video malaise theory only attributes this negative effect to TV. Alternatively, mobilization theory suggests that greater access to media leads to a "virtuous circle", in other words, a positive effect. Given such vastly different theories, this paper aims at analyzing the moderating effect that access to information through other media (TV and print) may have on building trust toward a blogger, as well as the effect that it would have on voting intention and attachment to the blogger and/or to the blogger's political. This is particularly relevant in local politics, where the media have a decisive role in providing mobilizing information that enables citizens to understand how local matters will affect their daily lives (Moy et al 2004).

\section{Media access and citizen behavior}

\section{Cognitive mobilization}

Inglehart (1970) was the first to coin the term cognitive mobilization (CM) to refer to the growing and widespread distribution among the population of the necessary political skills for relating to a large political community. This theory suggests that citizens may leave cast their partisan alignment aside seeking deeper deliberation as the cost of access to information decreases.

Dalton $(1984,2007)$ suggests that CM is brought about by two processes: first of all, an increase in the public's ability to process political information; second, a drop in the cost of acquiring that political information. Hence, in the modern era, given the high level of education achieved and the omnipresence of the media, one could expect a decrease in permanent alignment with a political party, given that citizens are cognitively mobilized and do not rely on the political approach provided by parties. Therefore, they can make their own decisions without basing them on traditional affective elements (Arzheimer 2006; Dalton 2007).

Access to information resources and other prerequisites for informed democratic citizenship have grown by equal measure as the modern democracies have become a more cosmopolitan, advanced industrial, information-based society. The relatively closed media environment of earlier decades has been replaced by globalized information networks from cable television and the Internet. Higher education levels also increase the ability of the average citizen to assimilate and utilize this 
information. Moreover, it is important that these civic skills are combined with a motivation to apply these skills to politics by political interest (Dalton 2012).

Barnes (1997) showed how the bases of citizen mobilization in general shift from traditional social anchors such as class and religion to an attachment to certain parties and movements and from these to $\mathrm{CM}$, revealing individual decisions based on processing information and perceiving values.

$\mathrm{CM}$ theory is at the core of citizens' relationships with their political representatives, and offers a scenario characterized by citizens who are capable of challenging their representatives' actions (Albright 2009), exerting a considerable effect on political thought and vote choice, thus leading to the existence of a differentiated, unaligned electorate (Dalton 2007).

Although CM is influenced by the changes that take place on a macro level, research on the subject must focus on the micro level, looking at individual behavior. Although over time the CM approach has been supported by several research papers, the theory itself predicts that its effect will diminish in the course of time (Albright 2009).

Several studies with similar approaches to that of CM suggest that as citizens with easy access to a high volume of information develop greater skills, it becomes increasingly difficult to establish the existence of partisan attachment among voters (Arzheimer 2006; Huber et al 2005). Meanwhile, Kuan and Lau (2002) confirm that $\mathrm{CM}$ complements the role of partisan attachment in their explanation of electoral behavior, establishing the existence of two patterns: partisan versus cognitive mobilization. Some cross-national evidence suggests that cognitive mobilization creates a new group of sophisticated independents, and the proportion of the public that qualifies as these new independents is generally increasing in Western democracies (Dalton 2007).

While less informed citizens vote according to partisan alignment, those best informed base their decisions on a larger number of variables. Voters with less political knowledge are less likely to recognize a suitable party or candidate given their preferences, each additional increment of knowledge tightens the connection between attitudes and the vote (Arnold 2012). On the other hand, in a view that is diametrically opposed to CM, Albright (2009) states that cognitive skills and access to mass media predict an increase in the probability that a citizen will express attachment to a political party.

If citizens focus their skills on other life domains, then the impact of increasing cognitive mobilization on politics will be limited. If these traits are combined, this can produce groups of citizens that can have the ability and motivation to understand the world of politics. In other words, the cognitive mobilization of the public, in combination with other social forces, may have changed the calculus of partisanship for some citizens (Dalton 2012).

\section{Political (de)/mobilization theories}

We can find the origin of the differing results related to $\mathrm{CM}$ in political (de)mobilization theories that analyze the effect of the media on the spread of feelings of political dealignment. Even though the media appear as agents with an 
influence on political life, the implications of their impact is highly disputed and difficult to establish, leading to media malaise/video malaise theories and to political mobilization theory, which offer opposing views.

The first of the two, the media malaise theory (Lang and Lang 1966; Weaver 1972), which has been widely supported, suggests that TV coverage of political news stories could have an effect on the electorate's view of public institutions. Video malaise theories argue that political communication processes have a negative impact on citizens' commitment. These arguments explain the constant decline of civic engagement and withdrawal of citizens from political life. According to this view, those politically disaffected and distrustful happen to be those who consume the largest volume of media, particularly TV (Robinson 1976). The reason for this may be that TV, more than print or radio, makes it easier to introduce the human element due its visual impact and cultural implications (Mutz and Reeves 2005).

According to the media malaise argument, the modern media-especially TVtend to create political cynicism and apathy, withdrawal from the sphere of public life, social isolation and consequently loss of social capital. Both the content and format of the modern media are seen as causes of the misery (Jenssen 2009). This has to be analyzed with particular caution, given that the degree of cynicism exhibited by politicians in their TV appearances has a negative effect on political trust (Mutz and Reeves 2005).

Research aimed at confirming the video malaise theory has led to its being at least partly refuted. Several studies posit that the use of TV newscasts as a source of political information is positively related to knowledge about candidates, and not to cynicism toward politicians (Leshner and McKean 1997). Mutz and Reeves (2005) find that TV promotes a style of political debate that provokes the audience's understanding of civilized debate and thereby creates political mistrust. This point was stressed in an article by Adriaansen et al (2010), in which the authors did not find a significant effect of news content on political cynicism, whereas among young voters exposure to news had a negative effect on the development of political cynicism. This behavior has been interpreted as a process of secondary socialization that may reverse the "spiral of cynicism".

In other cases, the focus of the analysis was placed on the different types of TV channels to which citizens have access. Aarts and Semetko (2003) confirmed that viewing public channels increases knowledge and participation, whereas doing so with commercial channels has negative effects. Therefore, while some citizens appear to exhibit a "spiral of cynicism", other seem to reveal a "virtuous circle". Years later, Jenssen (2009) suggested that neither exposure to public nor private channels contributes to increasing the overall level of political knowledge.

The second of the two theories, political mobilization, suggests that the media have a significant impact on the public, but in this case, maintaining and promoting commitment and democratic participation, contributing to democratic malaise (Holtz-Bacha 1990; Holtz-Bacha and Norris 2001; Newton 1999; Norris 2000b). Therefore, there is no evidence of media malaise being related to high levels of exposure to TV. Along the same lines, Norris (2000b) suggests and confirms the 
"virtuous circle" theory, according to which easy access to a broad range of information sources generates political trust (Norris 2000a, b).

In keeping with this theory, it has been suggested that both informal communication through personal relationships and formal communication via the media have a significant impact on an individual's likelihood to participate in elections, even though the former proves to be more influential than the latter (Schmitt-Beck and Mackenrodt 2010).

Stromback and Shehata (2010) find greater support for mobilization theories than for the media malaise view, suggesting that the key elements are political interest and news attention, where political interest is determined by news media exposure. In keeping with these results, Tworzecki and Semetko (2010) confirm the impact of media use on political knowledge and participation in political activities other than voting.

The actual arguments presented in the research literature are, of course, much more sophisticated and have far more nuances than this sketchy presentation. The "media malaise" thesis is partly a dummy created by the critics of the "thesis", and bundles a variety of arguments. One of the important nuances has to do with the difference between various media channels (Jenssen 2009). It appears that there are marked contrasts between TV and mass print media (Norris and Sanders 2003). Although Holtz-Bacha (1990) suggested that exposure to TV news and mass print media is not related to the presence of the elements that lead to political disaffection, it has been observed that print media readers relate to mobilization more than the TV viewers. However, this differing impact is associated with the type of medium chosen, since mass print media and TV are not significantly associated with video malaise measures (Newton 1999).

Several studies find that readers of quality newspapers tend to be significantly more politically active than the average TV viewer (Newton 1999). Despite this fact, Norris and Sanders (2003) do not find any superiority of print media over TV or even Internet newscasts.

The influence of news content on political trust is influenced by citizens' levels of prior trust and by the medium through which they get the news. For those with an initial distrust of politics, exposure to print media, as well as to TV, does not have a significant effect on subsequent levels of trust. However, for those who initially exhibit a high degree of trust, high exposure to TV news leads to weaker trust in government, whereas high exposure to print media leads to an increase in that trust (Avery 2009).

\section{Field work}

Development of the model

Questions of satisfaction, trust, and loyalty have also increased in importance in the online context. It is precisely this potential increase in consumer sovereignty that would also lead to the increased research related with the role of trust and commitment in online context (Chung and Shin 2010). The conventional 
explanatory model for blog use behavior includes the effect of satisfaction on commitment in the logical sequence between the components of relationship quality (satisfaction-trust-commitment) (Casaló et al 2008; Flavián et al 2006; Rufín et al 2012; Sanchez-Franco and Rondan-Cataluña 2010; Sánchez-Franco et al 2009), while also considering the direct relationship between attachment and satisfaction, trust, and commitment (Thomson 2006; Thomson et al 2005). What we have now added to the relationships mentioned-above is the impact of commitment on attachment to the blogger and the party he/she represents, as well as on the intention to vote the blogger or his/her party.

Relationship commitment may be defined as the enduring desire to maintain a relationship that is considered important and valuable, therefore, a party committed to a relationship is motivated to maintain it and will work for that purpose (Casaló et al. 2011).

Commitment, symbolizing the implicit or explicit assurance of service providers, refers to a willingness to develop and maintain a positive exchange relationship (Wu et al. 2009). Commitment induces customers to remain in the existing service and keeps them from trying competitors' services, and those consumers who show affective commitment are less attracted to competitors' promotions (Hur et al. 2011).

The term customer commitment encompasses the psychological and economic attachments that a customer might have toward a particular brand, store or product (Thomson et al. 2005). Many researchers have found commitment to be the key component of establishing and maintaining long-term relationships between business partners (Chung and Shin 2010). The concept of commitment is used as a predictor of members' actual behaviors in an online setting, and should be treated as an attitudinal factor that is emphasized when members acknowledge the value of continuing relationships (Hur et al. 2011).

Research in the area of commitment has identified two different types of customer commitment-affective and continuance. Economic or continuance commitment is characterized by the customers' need to stay in a relationship because of a lack of other alternatives or high switching costs, affective commitment is defined as the customers' emotional attachment to a particular brand or store-based on their identification with that store or brand (Iglesias et al. 2011). The literature suggests that the role of the more emotional component within commitment (affective commitment) can be key to further explain this relationship, and is rooted in positive feelings and preferences, and often leads to long-term partnerships (Iglesias et al. 2011; Wu et al. 2009).

When customers are affectively committed to a service company, they identify themselves with the company's vision and value, and in turn they are interested in the growth of the company (Hur et al. 2011). Commitment as a psychological attachment leads to customers' proactive behavior, such as positive word-of-mouth (Chung and Shin 2010; Hur et al. 2011; Royo-Vela and Casamassima 2011) or consumer retention (Zhang and Bloemer 2011).

As countries become more democratic, mass media come to assume a critical role, and as media become more free, their role increases (Camaj 2013). Although commitment has a determining effect on voting and on other important forms of 
political behavior (Britt 2003), it has been suggested that print media readers are more mobilized (Newton 1999), and therefore we can assume that access to different media will moderate the relationship between blog visitors' commitment to the blogger and their attachment and voting intention.

Cognitive mobilization suggests that citizens cast off their partisan alignment when information costs decrease and individuals develop certain skills (Inglehart 1970; Dalton 1984, 2007). On the one hand, the more media citizens consume, particularly TV, the less politically committed they become. These notions are partly based on the fact that TV makes it easier to include a human element that can generate cynicism, which has a negative effect on trust development (Jenssen 2009; Mutz and Reeves 2005). However, Adriaansen et al. (2010) obtained the opposite results when they argued that among young people, the greater the exposure to news content, the less cynical they will be. Lastly, it is important to note the existence of differing effects depending on the medium used by citizens; possible contrasts appear between TV and print media (Jenssen 2009; Norris and Sanders 2003).

Therefore, blog visits can be associated with greater citizen involvement and participation in political life (Mackinnon 2008; Rojas and Puig-i-Abril 2009; Touri 2009; Woodly 2008). But this relationship can prove more complex if we bear in mind that Internet users often use other media as well, and considering that there are doubts, according to a review of the literature, as to the impact that the use of these other media may have on blog visitors. To distinguish between all these possibilities, which theoretically could alter the conventional model of blogger behavior, we posit the following hypotheses:

$\mathrm{H}_{1 \mathrm{a}}$ : Access to print media moderates the relationship between the visitor's commitment and attachment to the blogger.

$\mathrm{H}_{1 \mathrm{~b}}$ : Access to TV moderates the relationship between the visitor's commitment and attachment to the blogger.

$\mathrm{H}_{2 \mathrm{a}}$ : Access to print media moderates the relationship between the visitor's commitment and attachment to the blogger's party.

$\mathrm{H}_{2 \mathrm{~b}}$ : Access to TV moderates the relationship between the visitor's commitment and attachment to the blogger's party.

$\mathrm{H}_{3 \mathrm{a}}$ : Access to print media moderates the relationship between the visitor's commitment to and intention of voting the blogger.

$\mathrm{H}_{3 \mathrm{~b}}$ : Access to TV moderates the relationship between the visitor's commitment to and intention of voting the blogger.

$\mathrm{H}_{4 \mathrm{a}}$ : Access to print media moderates the relationship between the visitor's commitment to and intention of voting the blogger's party.

$\mathrm{H}_{4 \mathrm{~b}}$ : Access to TV moderates the relationship between the visitor's commitment to and intention of voting the blogger's party.

The measurement scales that we used are adaptations of previous scales used by Thomson (2006); Cho (2006). More specifically, Thomson's scale (2006) was used to measure attachment, with 4 items; trust, satisfaction, and commitment, on the other hand, were drawn from Cho (2006), with four, three, and three items, respectively. Attachment to the blogger and the party he/she represents as well as the intention of voting were both analyzed according to one single factor (Appendix 1). 
Data gathering

Data were gathered between June 2009 and February 2010. Field work consisted of attaching a link to the blogs of 21 politicians, requesting visitors' participation in the study. Once visitors clicked on the request, they were redirected to a website with a questionnaire. A total of 283 users completed the questionnaire. For the survey to cover the entire ideological spectrum, we used blogs for politicians from right-wing (ten blogs, 142 questionnaires) and left-wing parties (11 blogs, 141 questionnaires). All blogs belonged to politicians active at a local level in large and mid-sized cities in Andalusia (Spain). $68 \%$ of those surveyed were male, with $78 \%$ of those surveyed in the age range of $20-50$ years. $70 \%$ of respondents had a university degree and $28 \%$ had completed secondary education. As regards the frequency of visits to the blog, $45 \%$ said they visited on a daily basis and $36 \%$ once a week. As regards the frequency with which they access printed newspapers and television, $78 \%$ of those surveyed said they visited them frequently and 12 and $11 \%$, respectively, occasionally.

\section{Analysis}

The scales initially proposed for performing the statistical analysis were adaptations of scales that had been validated in previous studies, and whose content we therefore could assume to be valid.

The statistical analysis of the behavior of the constructs in the model was performed with variance-based Structural Equation Modelling (SEM) (Reinartz et al. 2009) by applying the Partial Least Squares (PLS) method. PLS allows a simultaneous analysis of how well the measures relate to each construct (measurement model) and whether the hypothesized relationships are empirically true at a theoretical level (structural model) (Sosik et al 2009). PLS path modelling focuses on predicting the dependent variables (both latent and manifest). This objective is achieved by maximizing the explained variance $\left(R^{2}\right)$ of the dependent variables (Barroso et al. 2010).

PLS is primarily intended for causal-predictive analysis, where the problems explored are complex and prior theoretical knowledge is scarce. Certainly, as Chin (2010) states "it is under this backdrop of high complexity that PLS, regardless of whether applied under a strong substantive and theoretical context or limited/ exploratory conditions, comes to the fore relative to CBSEM". Thus, PLS is an appropriate technique to use in a theory-development situation, such as this research, given the complexity of the proposed relationships included in our model, which have been previously tested in partial models but not following a holistic approach. The proposed models and hypothesis testing is conducted using SmartPLS 2.0.M3 software (Ringle, Wende and Will 2008).

Analysis of the measurement model

To analyze the measurement model, we began with an analysis of the variables that make up the scale. Among these variables, only COMMIT3 had to be removed, 
because its factor loading was lower than 0.707 . Once that item had been removed, all remaining items met the defined requirements, both in terms of their loadings and in term of their significance level (Table 1). As shown in that table, all constructs containing more than one item had a Cronbach's alpha value that was higher than the minimum established by the theory.

Convergent validity was established by analyzing the Average Variance Extracted (AVE.), assuming that there is convergent validity if the AVE value of the constructs included in the model, and which are measured by more than one item, is higher than 0.5. (Table 1).

Table 2 shows that all indicators loaded more highly on their own constructs than on any other constructs.

To establish the discriminant validity, the AVE value must be higher than the variance shared by the construct and the other represented constructs. To simplify the comparison, each element along the main diagonal (square root of AVE) must be higher than the remaining elements in its row and the corresponding columncorrelations between constructs-(Barclay et al 1995). In our case (Table 3), we can state that, in any case, the values of the main diagonal are higher than those of the row and column in which they appear.

Table 1 Analysis of the scale

\begin{tabular}{|c|c|c|c|c|}
\hline & & $\begin{array}{l}\text { Original } \\
\text { sample } \\
\text { loadings }(\mathrm{O})\end{array}$ & $\begin{array}{l}\text { Standard } \\
\text { error } \\
\text { (STERR) }\end{array}$ & $\mathrm{T}$ statistics \\
\hline $\begin{array}{c}\text { AA (Cronbach's alpha }=1, \\
\left.R^{2}=0.2539, \mathrm{AVE}=1\right)\end{array}$ & AA1 & 1.0000 & - & - \\
\hline $\begin{array}{l}\mathrm{AP}(\text { Cronbach's alpha }=1 \\
R^{2}=0.1249, \mathrm{AVE}=1\end{array}$ & AP1 & 1.0000 & - & - \\
\hline \multirow{4}{*}{$\begin{array}{l}\text { Attachment (Cronbach's } \\
\text { alpha }=0.8533, \text { AVE }=0.6923 \text { ) }\end{array}$} & ATTACH1 & 0.8456 & 0.0231 & 36.6070 \\
\hline & ATTACH2 & 0.8426 & 0.0303 & 27.7805 \\
\hline & АTTACH3 & 0.8756 & 0.0204 & 42.7673 \\
\hline & ATTACH4 & 0.7595 & 0.0379 & 20.0169 \\
\hline \multirow{2}{*}{$\begin{array}{l}\text { Commitment (Cronbach's } \\
\text { alpha }=0.9377, R^{2}=0.1249, \\
\text { AVE }=0.9414)\end{array}$} & COMMIT1 & 0.9702 & 0.0064 & 150.2850 \\
\hline & COMMIT2 & 0.9702 & 0.0067 & 143.6311 \\
\hline \multirow{4}{*}{$\begin{array}{l}\text { Commitment (Cronbach's } \\
\text { alpha }=0.9669, R^{2}=0.1249 \\
\text { AVE }=0.9099)\end{array}$} & TRUST1 & 0.9644 & 0.0056 & 169.6883 \\
\hline & TRUST2 & 0.9696 & 0.0057 & 169.0580 \\
\hline & TRUST3 & 0.9585 & 0.0101 & 94.6594 \\
\hline & TRUST4 & 0.9223 & 0.0162 & 56.7713 \\
\hline \multirow{3}{*}{$\begin{array}{l}\text { Satisfaction (Cronbach's } \\
\qquad \begin{array}{l}\text { alpha }=0.9497, R^{2}=0.1249 \\
\text { AVE }=0.9099)\end{array}\end{array}$} & SAT1 & 0.9540 & 0.0079 & 120.0034 \\
\hline & SAT2 & 0.9435 & 0.0125 & 74.9078 \\
\hline & SAT3 & 0.9620 & 0.0077 & 124.6634 \\
\hline $\begin{array}{l}\text { VA }(\text { Cronbach's alpha }=1, \\
\left.\qquad R^{2}=0.4618, \text { AVE }=0.9099\right)\end{array}$ & VA1 & 1.0000 & - & - \\
\hline $\begin{array}{l}\text { VP (Cronbach's alpha }=1 \\
\left.R^{2}=0.1316, \mathrm{AVE}=0.9099\right)\end{array}$ & VP1 & 1.0000 & - & - \\
\hline
\end{tabular}


Table 2 Loadings and cross loadings

\begin{tabular}{lllllllll}
\hline & Attachment & AA & AP & Commitment & Trust & Satisfaction & VA & VP \\
\hline AA & 0.5322 & 1.0000 & 0.7883 & 0.5039 & 0.4949 & 0.5104 & 0.6996 & 0.6663 \\
AP & 0.3897 & 0.7883 & 1.0000 & 0.3535 & 0.3224 & 0.3680 & 0.5614 & 0.8638 \\
ATTACH1 & 0.8457 & 0.5209 & 0.3565 & 0.5798 & 0.5212 & 0.6312 & 0.5494 & 0.3669 \\
ATTACH2 & 0.8427 & 0.5523 & 0.3952 & 0.5159 & 0.6170 & 0.5529 & 0.5769 & 0.3865 \\
ATTACH3 & 0.8757 & 0.3480 & 0.2666 & 0.4618 & 0.4327 & 0.4591 & 0.4435 & 0.3247 \\
ATTACH4 & 0.7596 & 0.2936 & 0.2515 & 0.3877 & 0.2570 & 0.4080 & 0.3160 & 0.2748 \\
COMMIT1 & 0.5750 & 0.5110 & 0.3323 & 0.9703 & 0.6634 & 0.7550 & 0.6800 & 0.3261 \\
COMMIT2 & 0.5812 & 0.4669 & 0.3537 & 0.9702 & 0.6908 & 0.7838 & 0.6387 & 0.3779 \\
TRUST1 & 0.5769 & 0.5216 & 0.3490 & 0.6886 & 0.9645 & 0.7452 & 0.7069 & 0.3640 \\
TRUST2 & 0.5360 & 0.4390 & 0.2752 & 0.6634 & 0.9696 & 0.7158 & 0.6649 & 0.3178 \\
TRUST3 & 0.5641 & 0.5054 & 0.3314 & 0.6899 & 0.9586 & 0.7295 & 0.6811 & 0.3654 \\
TRUST4 & 0.4848 & 0.4168 & 0.2705 & 0.6176 & 0.9224 & 0.6713 & 0.6147 & 0.3261 \\
SAT1 & 0.5965 & 0.4837 & 0.3273 & 0.7463 & 0.7109 & 0.9541 & 0.6311 & 0.3333 \\
SAT2 & 0.5777 & 0.4672 & 0.3641 & 0.7259 & 0.6922 & 0.9436 & 0.6676 & 0.3867 \\
SAT3 & 0.6270 & 0.5075 & 0.3610 & 0.7931 & 0.7424 & 0.9620 & 0.6978 & 0.3661 \\
VA & 0.5822 & 0.6996 & 0.5614 & 0.6796 & 0.7002 & 0.6985 & 1.0000 & 0.5652 \\
VP & 0.4123 & 0.6664 & 0.8638 & 0.3628 & 0.3604 & 0.3795 & 0.5652 & 1.0000 \\
\hline
\end{tabular}

Table 3 Discriminant validity analysis

\begin{tabular}{lllllllll}
\hline & Attachment & AA & AP & Commit & Trust & Satis & VA & VP \\
\hline Attachment & 0.8320 & - & - & - & - & - & - & - \\
AA & 0.5322 & 1 & - & - & - & - & - & - \\
AP & 0.3896 & 0.7883 & 1 & - & - & - & - & - \\
Commit & 0.5958 & 0.5039 & 0.3535 & 0.9703 & - & - & - & - \\
Trust & 0.5677 & 0.4948 & 0.3224 & 0.6978 & 0.9539 & - & - & - \\
Satis & 0.6304 & 0.5104 & 0.3679 & 0.7929 & 0.7508 & 0.9533 & - & - \\
VA & 0.5821 & 0.6996 & 0.5613 & 0.6795 & 0.7001 & 0.6985 & 1 & - \\
VP & 0.4122 & 0.6663 & 0.8638 & 0.3628 & 0.3603 & 0.3795 & 0.5651 & 1 \\
\hline
\end{tabular}

Structural model analysis

In the Figure 1, we analyze the relationship between the constructs included in the structural model. The results are shown in Table 4 .

In our case (Fig. 1), all the relationships included in the model appeared to be significant. Thus, the attachment has a significant influence on satisfaction (path $\left.=0.6304, \quad t_{\text {value }}=13.4435\right)$ and commitment $\quad\left(\right.$ path $=0.1267, \quad t_{\text {value }}=$ 2.4344 ), satisfaction on trust (path $=0.7508, t_{\text {value }}=16.8834$ ) and commitment (path $=0.5573, t_{\text {value }}=7.4352$ ), and trust on commitment (path $=0.2075$, $\left.t_{\text {value }}=2.8096\right)$. Meanwhile, commitment has a positive effect on attachment to the blogger $\left(\right.$ path $=0.5039, t_{\text {value }}=8.2541$ ), attachment to the blogger's party 


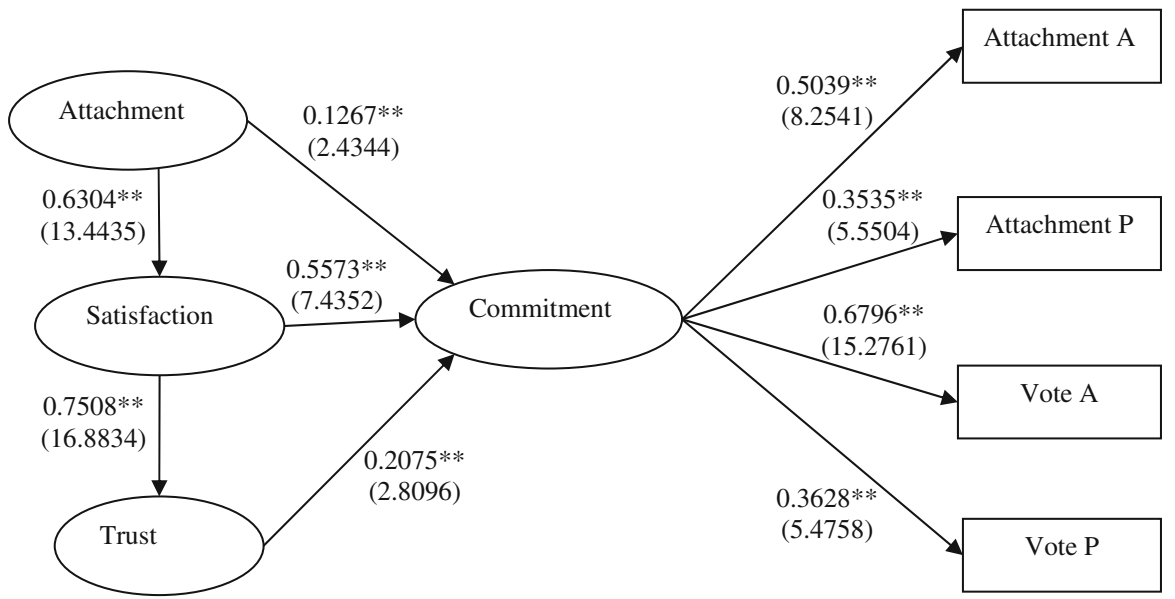

Fig. 1 Model tested

Table 4 Structural model analysis

\begin{tabular}{llllr}
\hline & $\begin{array}{l}\text { Original sample } \\
(\mathrm{O})\end{array}$ & $\begin{array}{l}\text { Sample mean } \\
(\mathrm{M})\end{array}$ & $\begin{array}{l}\text { Standard error } \\
\text { (STERR) }\end{array}$ & $\begin{array}{r}\text { T } \\
\text { statistics }\end{array}$ \\
\hline Attachment $\rightarrow$ Commitment & 0.1267 & 0.1256 & 0.0520 & 2.4344 \\
Attachment $\rightarrow$ Satisfaction & 0.6304 & 0.6357 & 0.0468 & 13.4435 \\
Commitment $\rightarrow$ AA & 0.5039 & 0.5009 & 0.0611 & 8.2541 \\
Commitment $\rightarrow$ AP & 0.3535 & 0.3486 & 0.0637 & 5.5504 \\
Commitment $\rightarrow$ VA & 0.6796 & 0.6786 & 0.0445 & 15.2761 \\
Commitment $\rightarrow$ VP & 0.3628 & 0.3588 & 0.0663 & 5.4758 \\
Trust $\rightarrow$ Commitment & 0.2075 & 0.2059 & 0.0739 & 2.8096 \\
Satisfaction $\rightarrow$ Commitment & 0.5573 & 0.5551 & 0.0750 & 7.4352 \\
Satisfaction $\rightarrow$ Trust & 0.7508 & 0.7533 & 0.0445 & 16.8833 \\
\hline
\end{tabular}

(path $\left.=0.3535, t_{\text {value }}=5.5504\right)$, the intention of voting the blogger (path $=0.6796$, $t_{\text {value }}=15.2761$ ), and the intention of voting the blogger's party (path $=0.3628$, $\left.t_{\text {value }}=5.4758\right)($ see also Table 4$)$.

Mediation analysis

Given the importance of the mediating effects in the research model, it is necessary to conduct a systematic analysis exploring these effects. We elected the bootstrapping strategy for the tests. Bootstrapping is a nonparametric resample procedure that does not impose the assumption of normality of the sampling distribution (Sun 2010). Considering that we had used PLS in this paper, we chose to use the test as proposed by Chin (2003) given the multiple advantages it has to offer (Sosik et al. 2009). Based on the repeated samplings, an empirical approximation of the indirect effects can be estimated and used to construct confidence intervals for the indirect effects. In addition, the $\mathrm{BC}$ bootstrap will generate a 95 percent confidence interval (CI) for each 
Table 5 Analysis of relationships mediated by commitment

\begin{tabular}{lll}
\hline Independent variable & $\begin{array}{l}\text { Dependent } \\
\text { variable }\end{array}$ & $\begin{array}{l}95 \% \text { Confidence } \\
\text { interval }\end{array}$ \\
\hline Attachment & Aa & $(0.0144,0.1074)$ \\
& Ap & $(0.0073,0.0906)$ \\
& Va & $(0.0169,0.1564)$ \\
Satisfaction & Vp & $(0.0077,0.0930)$ \\
& Aa & $(0.1888,0.3684)$ \\
& Ap & $(0.1140,0.2766)$ \\
Commitment & Va & $(0.2649,0.4817)$ \\
& Vp & $(0.1128,0.2850)$ \\
& Aa & $(0.0384,0.1960)$ \\
& Ap & $(0.0257,0.1385)$ \\
& Va & $(0.0532,0.2556)$ \\
& Vp & $(0.0268,0.1440)$ \\
\hline
\end{tabular}

Table 6 Analysis of moderating effects

\begin{tabular}{lllllll}
\hline & \multicolumn{3}{l}{ Use of print media } & & & Use of TV \\
\cline { 2 - 3 } \cline { 6 - 7 } & Value (significance) & Hypothesis & & Value (significance) & Hypothesis \\
\hline Commitment-AA & $-0.7990(2.1492)^{*}$ & $\mathrm{H}_{1 \mathrm{a}}$ (Accepted) & & $-0.4735(1.1224)$ & $\mathrm{H}_{1 \mathrm{~b}}$ (Rejected) \\
Commitment-AP & $-0.7059(2.0354)^{*}$ & $\mathrm{H}_{2 \mathrm{a}}$ (Accepted) & & $-0.9503(2.3017) *$ & $\mathrm{H}_{2 \mathrm{~b}}$ (Accepted) \\
Commitment-VA & $-0.5836(1.6884)^{*}$ & $\mathrm{H}_{3 \mathrm{a}}$ (Accepted) & & $-0.2369(0.6851)$ & $\mathrm{H}_{3 \mathrm{~b}}$ (Rejected) \\
Commitment-VP & $-0.5433(1.2416)$ & $\mathrm{H}_{4 \mathrm{a}}$ (Rejected) & & $-0.6413(1.2376)$ & $\mathrm{H}_{4 \mathrm{~b}}$ (Rejected) \\
\hline
\end{tabular}

$* p<0.05$ based on a one-tailed $t$-student distribution $(499) \cdot t_{(0.05 ; 499)}=1.6479$

mediator. If the interval for a mediator does not contain zero, it means the indirect effect of this mediator is significantly different from zero (Sun 2010).

Following this approach, we confirmed that the relationships that were mediated by commitment were significant, since none of the confidence intervals included a value of 0 (Table 5). In other words, not only are all the relationships of the antecedents and the consequences of commitment significant; in addition, each one of the relationships is significant on its own Table 6.

\section{Analysis of moderating effects}

The ability to detect the presence or absence of differences between groups, and to estimate the strength of the moderating effects, is important in studies attempting to show contingent effects (Qureshi and Compeau 2009). We proceeded to analyze the interaction effect for the case of the variables that allowed for its use (frequency of visits to print media and TV as a source of political information). According to Rigdon et al (1998), interaction effect is the most obvious method for analyzing moderating effects, and its use is recommended whenever possible (Henseler and Fassott 2010). 
Following this methodology, we analyzed the moderating role played by the use of print media and TV in the posited relationships. If we begin with print media, we find that its moderating effect is significant in the relationship between trust and commitment $\left(t_{\text {value }}=1.9233\right)$ and between commitment and attachment to the blogger $\left(t_{\text {value }}=2.1492\right)$ and his/her party $\left(t_{\text {value }}=2.0354\right)$ as well as between commitment and the intention of voting the blogger $\left(t_{\text {value }}=1.6884\right)$. The existence of a negative estimator indicates that the relationship is stronger the more that medium is used. Regarding the moderating role of the frequency of TV use to get political information, it occurs in the relationship between attachment and satisfaction $\left(t_{\text {value }}=4.220\right)$, between attachment and commitment ( $t_{\text {value }}=$ 2.1282), satisfaction and commitment (2.2180), and commitment and attachment to the blogger's party. Again, the relationship is stronger the more frequent use of the media is-in this case, TV. The only relationships that are not moderated in any case are the ones between satisfaction and trust and between commitment and the intention of voting the party represented by the blogger.

\section{Conclusions}

Modern democracies and the institutions on which they are based are facing growing disaffection among their citizens, which leads to lower participation. The use of technology has been identified as one of the possible ways of solving the problem, particularly through blogs, once it has been established that they contribute to increasing public participation both online and offline (Rojas and Puig-i-Abril 2009; Woodly 2008).

The purpose of this study was to examine the moderating role that access to other media as sources of information may have in the development of commitment and in the behavior it generates. It is important to remember that the theories on the subject are contradictory: while the cognitive mobilization theory argues that the greater users' access to the media, the weaker their partisan attachment and their involvement in political life (which could result in a lower voting intention) will be, other theories focus on the damaging role of a certain medium (video malaise) or defend the opposite view, as is true of the mobilization theory.

According to the results we obtained, in the case of political blog visitors we must reject the cognitive mobilization and video malaise theses, as the greater users' access to TV and print media, the stronger the relationships will be. The behavior of the relationships we analyzed is in keeping with the assumptions of mobilization theory, specifically those studies that suggest differing roles of TV and print media, which appear as complementary in our study. Thus, the more frequently TV is watched, the greater the development of commitment will be, and the more frequently print media are read, the greater attachment will be to the blogger and his/her party as well as the intention of voting the blogger.

Our results are along the lines of the findings made by Albright (2009), who suggests that the more users read newspapers and watch TV, the stronger the attachment they develop, and by Tworzecki and Semetko (2010), for whom the use of multiple media is associated with citizens' behavior, including voting. 


\section{Discussion of results}

To posit our conclusions and proceed with their analysis, we must bear in mind that when we analyze visitors to political blogs we are dealing with a group of citizens with an interest in politics, which leads to a greater relevance of mobilization theories (Stromback and Shehata 2010). Blogs and social networks are becoming sources of information for final consumers and other news outlets that transform what they find in the Internet into a news story for final consumers. Here everything becomes blurred: the goal of informing people overlaps with sharing and reinforcing common feelings and attitudes that frequently represent the goal of the social networks that originate in the news (Mancini 2013).

Particularly noteworthy among the results obtained is the role of TV in generating attachment, which leads to greater development of commitment, both directly and indirectly through satisfaction. In addition, as would be expected based on the approaches in previous studies (Mutz and Reeves 2005), under no circumstances did TV viewing have an effect on developing trust and on the impact of trust on commitment. This fact may be related to the nature of TV, and particularly to the development of cynicism that is associated with trust. In addition, in our case, conversely to Avery (2009), high exposure to print media did not appear to lead to greater trust.

When commitment to the blogger is developed, it tends to have more of an influence on the visitor's attachment and voting intention regarding the blogger than concerning the political party. The more newspapers citizens read, the stronger the relationship between their commitment and attachment to and their likelihood of voting the blogger, and the stronger their partisan attachment. These results are in keeping with those obtained by Newton (1999), according to whom reading print media is mostly associated with mobilization. Watching news on TV, on the other hand, only moderates the relationship between commitment and partisan attachment, which grows along with viewing frequency.

However, the research presented here does not support the thesis according to which blogs replace traditional media as a source of information about political developments. Traditional media actually seem to be complemented by political blogs, since although in many different ways TV viewing favors the development of commitment, its impact on Internet users' attachment and behavior is greater the more print media they read.

\section{Practical implications}

The results we obtained enable us to suggest several different strategies, depending on the stage in the political cycle in which the blogger happens to be. If elections are not going to be held in the near future, the blogger's main goal should be to get visitors to develop commitment to the blog. There are several alternative ways of achieving this goal: making comments about news items or events that have been broadcast on TV to try to get visitors to use that medium; mentioning political programs in the blogger's commentaries or even in responses to viewers' contributions; trying to promote his/her own TV appearances; and, perhaps the 
most complex but effective method, creating hyperlinks to the medium's website or even hosting the blog on the TV channel's website.

If elections are on the horizon, the blogger's priority ought to be to shift visitors' focus toward news items appearing in print media so that their commitment can lead to actual behavior on election day. In order to do so, in addition to the strategies mentioned-above being applied to print media, the blogger should try to publish opinion articles in the print media.

In terms of recommending visits to other media, it is important that visitors do not perceive these recommendations as implicit sponsoring of online communications, because that could damage trust and brand loyalty, particularly if the user's emotional connection to the brand is threatened (Ashley and Leonard 2009).

It is important to place our results in the appropriate context. Politicians must make a bigger effort to develop blog visitor commitment, because, given the ongoing drop in print media readership, it is more difficult for the mobilizing effect to take place. Something similar occurs with access to TV. In this case, we are not faced so much with loss of viewers as with fragmentation of the audience as it moves toward private channels. It is important to bear in mind that while the literature suggested that public channels boosted participation, which was not the case for private channels (Aarts and Semetko 2003), it was later observed that neither one of these two kinds of channels increased political knowledge (Jenssen 2009).

\section{Limitations}

This study has limitations both in terms of the sample size-a larger sample would enable us to extrapolate our results more accurately-and of the possibility of extending the study over a longer period of time, which would lead to higher-quality conclusions. Furthermore, a distinction could have been made between the type of channel (public or private) that the blog visitor has access to, as well as the kind of program he/she tends to watch.

\section{Appendix}

See Table 7.

Table 7 Measurement scales

\begin{tabular}{ll}
\hline Construct & Item \\
\hline Attachment & $\begin{array}{l}\text { I feel better if the blogger did not leave us for long time periods } \\
\text { I would miss the blogger if he left politics } \\
\text { It would upset me if the blogger left politics } \\
\text { It would distress me if the blogger left politics }\end{array}$ \\
\hline
\end{tabular}


Table 7 continued

\begin{tabular}{ll}
\hline Construct & Item \\
\hline Satisfaction & As a citizen, I have a high quality relationship with the blogger \\
I am happy with the blogger's efforts toward citizens \\
I am satisfied with my relationship with the blogger (inverse) \\
Regarding my relationship with the blogger, I feel...Discontented-Content \\
Regarding my relationship with the blogger, I feel...Sad-Happy \\
Regarding my relationship with the blogger, I feel...Upset-Pleased \\
Regarding my relationship with the blogger, I feel...Dissatisfied-Satisfied \\
The blogger conveys a feeling of trust \\
I trust the blogger \\
The blogger gives me the impression that he is trustworthy \\
If we could not do something for ourselves, I would want the blogger to make the \\
Trust \\
If the blogger's actions could not be controlled, I hope that he would perform his task well \\
I trust the blogger to do the things we cannot do by ourselves \\
I generally do not trust the blogger (inverse) \\
The promises made by the blogger are reliable \\
I wish to remain as a follower of the blogger \\
I am loyal to the blogger \\
Even if it was difficult to follow the blogger, I would continue to do so \\
Commitment
\end{tabular}

\section{References}

Aarts, K., \& Semetko, H. A. (2003). The divided electorate: media use ad political involvement. The Journal of Politics, 65(3), 759-784.

Adriaansen, M. L., van Praag, P., \& de Vreese, C. H. (2010). Substance matters: how news content can reduce political cynism. International Journal of Public Opinion Research, 22(4), 433-457.

Albright, J. J. (2009). Does political knowledge erode political attachments?: A review of the cognitive mobilization thesis. Electoral Studies, 28(2), 248-260.

Arnold, J. R. (2012). The electoral consequences of voter ignorance. Electoral Studies, 31, 796-815.

Arzheimer, K. (2006). Dead men walking?: party identification in Germany, 1977-2002. Electoral Studies, 25, 791-807.

Ashley, C., \& Leonard, H. A. (2009). Betrayed by the Buzz? Covert content and consumer-brand relationships. Journal of Public Policy and Marketing, 28(2), 212-220.

Aurier, P., \& N'Goala, G. (2010). The differing and mediating roles of trust and relationship commitment in service relationship maintenance and development. Journal of the Academy of Marketing Science, $38,303-325$.

Avery, J. M. (2009). Videomalaise or virtuous circle? The influence of the news media on political trust. International Journal of Press-Politics, 14(4), 410-433.

Barclay, D., Higgins, C., \& Thompson, R. (1995). The Partial least squares (PLS) approach to causal modelling: personal computer adoption and use as an illustration. Technology Studies Special Issue on Research Methodology, 2(2), 285-309.

Barnes, S. H. (1997). Electoral behavior and comparative politics. In M. I. Lichbach \& M. S. Zuckerman (Eds.), Comparative politics: rationality, culture, and structure. New York: Cambridge University Press.

Barroso, C., Gabriel, C., \& Roldán, J. L. (2010). Applying maximum likelihood and PLS on different sample sizes: studies on SERVQUAL model and employee behaviour model. In V. Esposito Vinzi, 
W. W. Chin, J. Henseler, \& H. Wang (Eds.), Handbook of partial least squares: concepts, methods and applications (pp. 427-447). Berlin: Springer.

Britt, T. W. (2003). Motivational and emotional consequences of self-engagement: voting in the 2000 US presidential election. Motivation and Emotion, 27(4), 339-358.

Camaj, L. (2013). The media's role in fighting corruption: media effects on governmental accountability. The International Journal of Press/Politics, 18(1), 21-42.

Casaló, L. V., Flavián, C., \& Guinalíu, M. (2008). Fundaments of trust management in the development of virtual communities. Management Research News, 31(5), 324-338.

Casaló, L. V., Flavián, C., \& Guinalíu, M. (2011). The generation of trust in the online service and product distribution: the case of spanish electronic commerce. Journal of Electronic Commerce Research, 12(3), 199-213.

Chin, W. W. (2003). A permutation procedure for multigroup comparison of PLS Models. In M. Vilares et al. (Ed.), PLS and related methods. Proceedings of the PLS'03 International Symposium: Decisia.

Chin, W. W. (2010). How to write up and report PLS analyses. In V. Esposito Vinzi, W. W. Chin, J. Henseler, \& H. Wang (Eds.), Handbook of partial least squares: concepts, methods and applications (pp. 655-690). Berlin: Springer.

Cho, J. (2006). The mechanism of trust and distrust formation and their relational outcomes. Journal of Retailing, 82(1), 25-35.

Chung, K.-H., \& Shin, J.-I. (2010). The antecedents and consequents of relationship quality in internet shopping. Asia Pacific Journal of Marketing and Logistics, 22(4), 473-491.

CIS (2012). Centro de Investigaciones Sociológicas; Spanish Center for Sociological Research. http://www. cis.es/cis/export/sites/default/-Archivos/Indicadores/documentos_html/TresProblemas.html. Accessed 4 Feb 2013.

Dalton, R. J. (1984). Cognitive mobilization and partisan dealignment in advanced industrial democracies. Journal of Politics, 46, 264-284.

Dalton, R. J. (2007). Partisan mobilization, cognitive mobilization, and the changing American electorate. Electoral Studies, 26, 274-286.

Dalton, R. J. (2012). Partisans and the changing German electorate. Electoral Studies, 31, 35-45.

Eveland, W. P., \& Thomson, T. (2006). Is it talking, thinking, or both? A lagged dependent variable model of discussion effects on political knowledge. Journal of Communication, 56, 523-542.

Flavián, C., Guinalíu, M., \& Gurrea, R. (2006). The role placed by perceived usability, satisfaction and consumer trust on website loyalty. Information and Management, 43, 1-14.

Henseler, J., \& Fassott, G. (2010). Testing moderating effects in PLS path models: an illustration of available procedures. In V. Esposito, et al. (Eds.), Handbook of partial least squares, springer handbooks of computational statistics (pp. 713-735). Berlin: Springer.

Holtz-Bacha, C. (1990). Videomalaise revisited: Media exposure and political alienation in West Germany. European Journal of Communication, 5(1), 73-85.

Holtz-Bacha, C., \& Norris, P. (2001). To entertain. Inform, and educate: still the role of the public televsision in the 1990s? Political Communication, 18(2), 123-140.

Huber, J. D., Kernell, G., \& Leoni, E. L. (2005). Institutional context, cognitive resources, and party attachments across democracies. Political Analysis, 13, 365-386.

Hur, W.-M., Ahn, K.-H., \& Kim, M. (2011). Building brand loyalty through managing bran community commitment. Management Decision, 49(7), 1194-1213.

Iglesias, O., Singh, J. J., \& Batista-Foguet, J. M. (2011). The role of brand experience and affective commitment in determining brand loyalty. Brand Management, 18(8), 570-582.

Inglehart, R. (1970). Culture shift in advanced industrial society. New Jersey: Princeton University Press.

Jenssen, A. T. (2009). Does public broadcasting make a difference? political knowledge and electoral campaigns on television. Scandinavian Political Studies, 32(3), 247-271.

Kim, Y. C., \& Ball-Rokeach, S. J. (2006). Civic engagement from a communication infrastructure perspective. Communication Theory, 16, 173-197.

Kuan, H.C., \& Lau, S.K. (2002). Cognitive mobilization and electoral support for the Democratic Party in Hong Kong. Electoral Studies, 21(4), 561-582.

Lang, K., \& Lang, G. (1966). The Mass Media and Voting. In B. Berelson \& M. Janowitz (Eds.), Reader in public opinion and communication (pp. 455-472). New York: Free Press.

Leshner, G., \& McKean, M. L. (1997). Using TV news for political information during an off-year election: effects on political knowledge and cynism. Journalism and Mass Communication Quarterly, 74(1), 69-83. 
Mackinnon, R. (2008). Flatter world and thicker walls? Blogs, censorship and civic discourse in China. Public Choice, 134, 31-46.

Mancini, P. (2013). Media fragmentation, party system, and democracy. The International Journal of Press Politics, 18(1), 43-60.

Moy, P., McCluskey, M. R., McCoy, K., \& Spratt, M. (2004). Political correlates of local news media use. Journal of Communication, 54, 532-546.

Mutz, D. C., \& Reeves, B. (2005). The new videomalaise: effects of televised incivility on political trsut. The American Political Science Review, 99(1), 1-15.

Newton, K. (1999). Mass media effects: mobilization or media malaise. British Journal of Political Science, 29, 577-599.

Norris, P. (2000a). The impact of television on civic malaise. In S. J. Pharr \& R. D. Putnam (Eds.), Disaffected democracies. New Jersey: Princeton University Press.

Norris, P. (2000b). A virtuous circle. New York: Cambridge University Press.

Norris, P., \& Sanders, D. (2003). Message or medium? Campaign learning during the 2001 British general election. Political Communication, 20(3), 233-262.

Qureshi, I., \& Compeau, D. (2009). Assessing between-group differences in information systems research: a comparison of covariance-and component-based SEM. MIS Quarterly, 33(1), 197-214.

Reinartz, W., Michael, H., \& Henseler, J. (2009). An empirical comparison of the efficacy of covariancebased and variance-based SEM. International Journal of Research in Marketing, 26(4), 332-344.

Rigdon, E. E., Schumacker, R. E., \& Wothke, W. (1998). A comparative review of interaction and nonlinear modelling. In R. E. Schumacker \& G. A. Marcoulides (Eds.), Interaction and nonlinear effects in structural equation modeling (pp. 1-16). Mahwah: Lawrence Erlbaum.

Ringle, C. M., Wende, S. and Will, A. (2008). SmartPLS 2.0 (Beta). University of Hamburg: Hamburg, Germany, 2005, Available from http://www.smartpls.de (accessed May 20).

Robinson, D. (1976). A theory of party competition. London: Wiley.

Rojas, H., \& Puig-i-Abril, E. (2009). Mobilizers mobilized: information expression, mobilization and participation in the digital age. Journal of Computer-Mediated Communication, 14, 902-927.

Royo-Vela, M., \& Casamassima, P. (2011). The influence of belonging to virtual brand communities on consumers' affective commitment, satisfaction and word-of-mouth advertising. Online Information Review, 35(4), 517-542.

Rufín, R., Medina, C., Rey, M. (2012). Building trust and commitment to blogs. The Service Industries Journal. doi:10.1080/02642069.2013.719886.

Sanchez-Franco, M., \& Rondan-Cataluña, F. J. (2010). Connection between customer emotions and relationship quality in online music services. Behaviour and Information Technology, 29(6), 633-651.

Sánchez-Franco, M. J., Villarejo, A. F., \& Martín, F. A. (2009). The moderating effect of gender on relationship quality and loyalty toward Internet service providers. Information and Management, 46, 196-202.

Schmitt-Beck, R., \& Mackenrodt, C. (2010). Social networks and mass media as mobilizers and demobilizers: a study of turnout at a German local elections. Electoral Studies, 29, 392-404.

Sha, D. V., Cho, J., Nah, S., Gothieb, M., Hwang, H., Lee, N., et al. (2007). Campaign ads, online messaging, and participation: extending the communication mediation model. Journal of Communication, 57, 676-703.

Sosik, J. J., Kahai, S. S., \& Piovoso, M. J. (2009). Silver bullet or voodoo statistics? A primer for using the partial least squares data analytic technique in group and organization research. Group and Organization Management, 34(1), 5-36.

Stromback, J., \& Shehata, A. (2010). Media Malaise or a virtuous circle? Exploring the casual relationships between news media exposure, political news attention and political interest. European Journal of Political Research, 49(5), 575-597.

Sun, H. (2010). Sellers' trust and continued use of online market places. Journal of the Association for Information Systems, 11(4), 182-211.

Thomson, M. (2006). Human brands: investigating antecedents to consumers' strong attachments to celebrities. Journal of Marketing, 70(July), 104-119.

Thomson, M., MacInnis, D. J., \& Park, C. W. (2005). The ties that bind: measuring the strength of consumers' emotional attachments to brands. Journal of Consumer Psychology, 15(1), 77-91.

Touri, M. (2009). News blogs: strengthening democracy through conflict prevention. Aslib Proceedings New Information Perspectives, 61(2), 170-184. 
Tworzecki, H., \& Semetko, H. A. (2010). Media uses and effects in new democracias: the case of Poland's 2005 parliamentary and presidential elections. International Journal of Press-Politics, 15(2), 155-174.

Weaver, P. (1972). Is television news biased. Public Interest, 26, 57-74.

Woodly, D. (2008). New competencies in democratic communication? Blogs, agenda setting and political participation. Public Choice, 134, 109-123.

Wu, J. J., Chen, Y. H., \& Chung, Y. S. (2009). Trust factors influencing virtual community members: a study of transaction communities. Journal of Business Research, 63(9/10), 1025-1032.

Zhang, J., \& Bloemer, J. (2011). Impact of value congruence on affective commitment: examining the moderating effects. Journal of Service Management, 22(2), 160-182. 